\title{
Metastasis of Osteosarcoma to the Abdomen: A Report of Two Cases and a Review of the Literature
}

\author{
Robert Serpico $^{a} \quad$ Jeffrey Brown ${ }^{b}$ Alan Blank ${ }^{c}$ Kevin Jones $^{a}$ \\ R. Lor Randalld John Groundland ${ }^{a}$
}

aDepartment of Orthopedics, Sarcoma Service, University of Utah, Huntsman Cancer Institute, Salt Lake City, UT, USA; bUniversity of Miami Miller School of Medicine, Miami, FL, USA; 'Department of Orthopedic Surgery, Sarcoma Service, Rush University, Rush Medical Center, Chicago, IL, USA; dDepartment of Orthopedic Surgery, University of California, Davis, UC Davis Medical Center, Sacramento, CA, USA

\section{Keywords}

Metastatic osteosarcoma - Abdominal metastasis - Nonpulmonary osteosarcoma metastasis . Distant metastasis

\begin{abstract}
Two cases of primary distal femur osteosarcoma with subsequent metastasis to the abdomen are presented. In both cases, the development of abdominal metastasis was quickly followed by patient decline and death. A review of the literature was performed, assessing the presentation and survival of patients with osteosarcoma metastasized to the abdomen. As illustrated by the current cases and the literature review, abdominal metastasis in osteosarcoma is often a late manifestation and terminal prognostic indicator. Nonetheless, early detection and prompt intervention of this less common site of disease metastasis may improve patient care and palliative therapy.

(C) 2021 The Author(s).

Published by S. Karger AG, Basel
\end{abstract}

\section{Introduction}

This report will add value to the literature by clearly describing the clinical course 2 patients experienced with this metastatic pattern; in addition, the paper will provide practitioners and future investigators a concise, clear, and thorough review of the literature. The result of presenting these data would be an adjustment in clinical practice, whereby medical

\section{Karger"}


providers who manage osteosarcoma surveillance will be more attuned to abdominal manifestations of late metastasis, and they will be more prepared for the implications of that presentation on treatments and prognosis.

Primary osteosarcoma of bone is an aggressive malignancy with a metastatic pattern that favors the lungs primarily and the bones secondarily. Nonpulmonary, nonosseous metastases of osteosarcoma have been described in the literature, but the rare nature of this metastatic pattern has precluded the systematic study of these events. As presented, abdominal metastasis of osteosarcoma is often a late manifestation and terminal prognostic indicator. Nonetheless, early detection and prompt intervention of this less common site of disease may improve patient care and palliative therapy.

Osteosarcoma is the most common primary bone sarcoma, with an estimated annual incidence of 800-900 patients per year in the United States [1-3]. While the historical 5-year survival rate of localized, nonmetastatic osteosarcoma at presentation improved from 15 to $67 \%$ with the development and implementation of multiagent cytotoxic chemotherapy agents in the 1970s, this rate has plateaued despite ongoing efforts [4-7]. As with all sarcomas, the cause of death in patients with osteosarcoma is related to the development of metastatic disease. In osteosarcoma, the pattern of metastasis is well established, favoring the lungs in $>90 \%$ of known metastatic cases, through an assumed hematogenous route $[8,9]$. Nonpulmonary sites of metastasis of osteosarcoma are also well described, with metastasis to bone being the most common nonpulmonary site, occurring in approximately $5-10 \%$ of cases [9]. Nonpulmonary, nonosseous sites of metastatic osteosarcoma are considered rare, and reports of these cases are scarce in the literature. However, autopsy studies indicate that the rates of nonpulmonary, nonosseous metastasis in osteosarcoma may be higher than realized in clinical practice $[8,10]$. We present 2 cases of osteosarcoma metastasizing to the abdomen and a review of the literature.

\section{Case Presentations}

\section{Case 1}

A 10-year-old girl with no known medical issues presented to her primary care physician in October 2016 with complaints of left thigh and knee pain. The pain had been present for 1 month and was slowly getting worse. A radiograph was taken and a lesion was noted in the distal femoral metaphysis. The radiographs of the femur were concerning for an osteosarcoma, demonstrating a lytic lesion with an osseous matrix and an incomplete periosteal reaction. Immediate referral was made to an orthopedic oncologist, who saw her the next day. Magnetic resonance imagings (MRI) of the left femur was performed; the MRI correlated with the radiographs, corroborating aggressive features, including heterogeneous signal, contrast enhancement, soft tissue extension of the mass, and peritumoral edema. The patient was taken to the operating room for an open biopsy. Intraoperative pathologic assessment on frozen sections was consistent with osteosarcoma: pleomorphic spindle cells with nuclear atypia and associated osteoid. Staging was completed with computed tomography (CT) of the chest and a whole-body bone scan. The chest CT demonstrated two 1-mm nodules of indeterminate significance and the bone scan showed uptake only in the left femur. The final pathology confirmed the diagnosis of conventional osteosarcoma. The case was presented at the multidisciplinary sarcoma tumor board, and the patient began neoadjuvant chemotherapy 2 weeks after initial presentation. The multiagent cytotoxic treatment regimen proceeded according to the Children's Oncology Group AOST 0331 protocol, including doxorubicin, cisplatin, and methotrexate. The patient completed the full neoadjuvant course and was restaged with an MRI of the femur, with and without contrast, and a CT of the chest. Restaging revealed stable

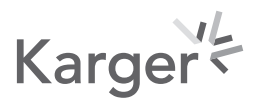


disease in the distal femur, albeit with a small pathologic fracture, and resolution of the two 1 -mm nodules in the lungs, without development of any new nodules. Seventeen weeks after starting chemotherapy, the patient underwent local control with wide surgical resection and endoprosthetic reconstruction with a metallic distal femur replacement. Surgical pathology revealed widely negative surgical margins with $>2 \mathrm{~cm}$ of surrounding uninvolved tissue and $90 \%$ necrosis. Chemotherapy was resumed per the AOST 0331 guidelines 3 weeks after surgery. The patient completed the course of chemotherapy 10 months after starting treatment, tolerating treatment with minimal interruptions. End-of-therapy scans were completed, revealing no observable disease on local imaging of the femur (radiographs), imaging of the lungs (CT), nor distant, nonpulmonary sites (positron emission tomography [PET]-CT).

The patient began surveillance every 3 months per the National Comprehensive Cancer Network guidelines for osteosarcoma [11]. Six months after completion of chemotherapy, 16 months after initial presentation with knee pain, the patient presented to the medical oncologist with abdominal pain. The pain had started 2 months previously and had initially been minor, so it had been treated symptomatically at home. On CT of the chest, a portion of the abdomen could be seen, revealing fluid around the spleen and liver, as well as two enlarged pericardial lymph nodes and a 2-mm nodule in the lung. Given the abdominal pain and the CT chest findings, a contrasted CT of the abdomen and pelvis was obtained by her medical oncologist. The abdominal CT demonstrated a large left lower quadrant mass $(13 \times 11 \times 10 \mathrm{~cm})$ with mineralization, a smaller adjacent mass, multiple masses throughout the abdominal cavity, and ascites (Fig. 1). Four days later, a biopsy performed in the Interventional Radiology suite confirmed the diagnosis of metastatic osteosarcoma to the abdomen. The institution's Sarcoma Tumor Board decided that the burden of disease was too extensive for surgical intervention and considered palliative radiation and/or chemotherapy. However, the symptoms rapidly declined with suspected hemorrhage of the abdominal mass, resulting in hemodynamic instability. The patient was treated with supportive measures and entered hospice care. She died of disease 1 month after diagnosis of abdominal metastasis, 3 months after the onset of abdominal pain, 19 months after initial diagnosis of her disease.

\section{Case 2}

An otherwise healthy 45-year-old man sought orthopedic evaluation in December 2014 after experiencing 2 years of worsening right thigh pain. MRI at that time displayed a large, heterogeneous, contrast-enhancing lesion involving the distal right femoral metadiaphysis extending through the cortex into the anterior compartment without skip lesions. The patient was referred to a comprehensive cancer center for evaluation by a dedicated, multidisciplinary sarcoma service. An open biopsy was then performed, providing a tissue diagnosis of fibroblastic osteosarcoma. A CT of the chest and a whole-body bone scan completed the staging. The chest CT revealed two 2-mm, indeterminate nodules in the lungs, and the bone scan demonstrated radionuclide absorption at the site of the distal femoral lesion alone. Two weeks after presentation to the cancer center, the patient began neoadjuvant chemotherapy with doxorubicin, cisplatin, and high-dose methotrexate. He completed the neoadjuvant chemotherapy regimen according to the AOST 0331 protocol and had restaging studies prior to planned local control with wide surgical resection and limb salvage. No new sites of disease were noted and the lung nodules were stable. Surgical resection and endoprosthetic reconstruction with a compressive osteo-integrative device (Compress, Biomet) occurred 4 months after initial presentation. Pathologic assessment of the resected specimen revealed highgrade fibroblastic osteosarcoma with $60 \%$ necrosis. Unfortunately, malignancy-positive surgical margins were identified, and the patient underwent revision resection 1 month later; the re-resected specimen was reported to be negative for residual tumor.

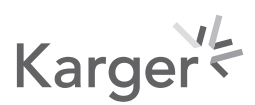



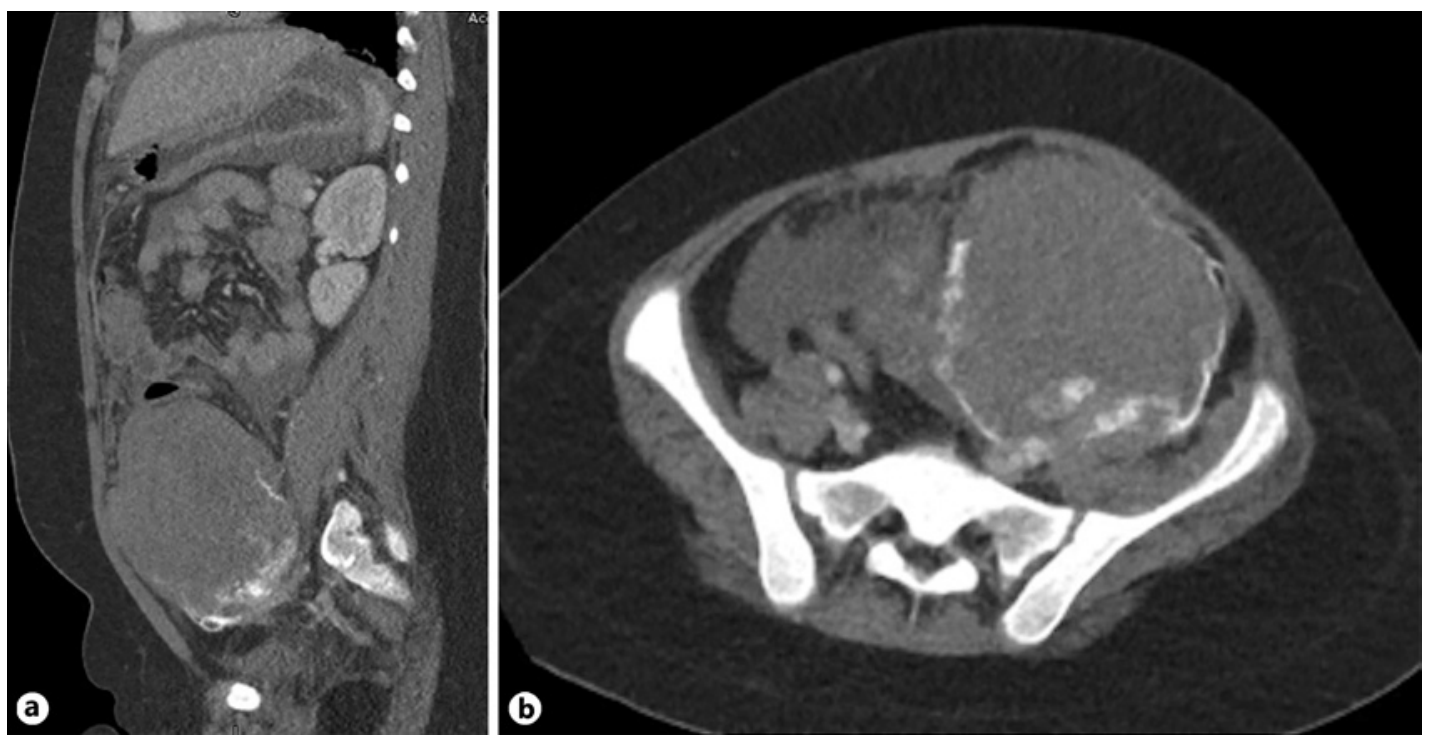

Fig. 1. Coronal (a) and axial (b) CT of the abdomen in a 10-year-old girl with a primary osteosarcoma of the distal femur. The abdominal mass presented 6 months after completion of chemotherapy. Subsequent biopsy confirmed the diagnosis of osteosarcoma metastasis to the peritoneal cavity. CT, computed tomography.

On the first postoperative surveillance scans, 3 months after local control, chest CT revealed multiple new lesions throughout the lungs bilaterally, consistent with metastatic osteosarcoma. These nodules were $<6 \mathrm{~mm}$ in dimension and were therefore not amenable to biopsy. In light of the poor necrosis rate and the patient's poor tolerance of neoadjuvant chemotherapy but the development of pulmonary nodules, the potential benefit of continuing the AOST 0331 treatment was discussed. Alternatives were explored, including gemcitabine/ doxetaxol, ifosfamide/etoposide, or pazopanib. Despite the presence of concerning pulmonary nodules, the patient opted to hold on to additional medical treatments until demonstration of further progressive disease. At this same time, the patient experienced a twisting mechanism of injury to the operative extremity, resulting in failure of the connection between the compress endoprosthesis device and the host bone. This was addressed surgically with revision of the orthopedic construct, changing the Compress device to a cemented, stemmed prosthesis.

Eight months later, 15 months after initial presentation, the CT demonstrated enlarging nodules, now numbering 12 lesions measuring 1-2 cm, and new interstitial edema. Concurrently, a mass was noted at the distal femur surgical site, concerning for local recurrence. Both the thigh mass and the pulmonary masses were biopsied, and were histologically consistent with osteosarcoma. The patient began pazopanib treatment, having refused more aggressive medical regimens due to prior intolerance of the AOST 0331 protocol. He tolerated pazopanib well and, after 6 months of pazopanib therapy, patient underwent LLL and LUL pulmonary wedge resections without complication. Pulmonary metastatic disease continued to progress, and the patient underwent RLL and RUL wedge resections 5 months after the left. Amputation of the lower extremity had been discussed with the patient, but was delayed until the end of medical treatment in order to assess disease response. During consultation for the above knee amputation, now 27 months after presentation, the patient complained of abdominal pain. On detailed history and physical exam, it was noted that he had been having fever for 3 days to $39^{\circ} \mathrm{C}$, sharp abdominal pain, nausea, loose stools, decreased appetite, and insomnia. 

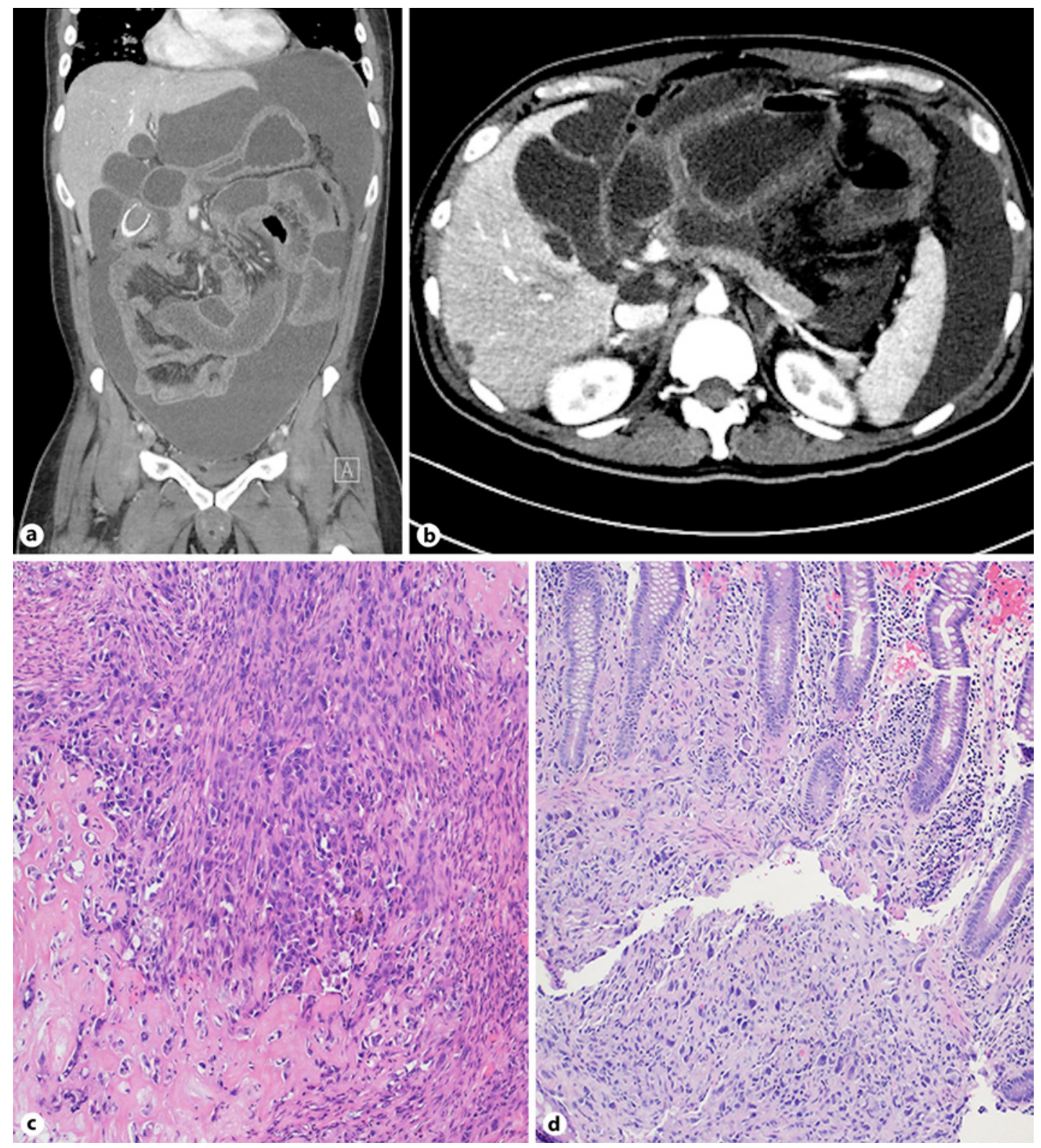

Fig. 2. a, b Coronal (a) and axial (b) CT of the abdomen and pelvis in a 45-year-old man with metastatic osteosarcoma to the lungs, abdomen, and retroperitoneal space. Note the large volume of ascites, prominent enhancement of the peritoneal surfaces, and omental caking. Nodular lesions could be seen in the liver, adrenal gland, and pericolonic gutters. $\mathbf{c}$ The patient's thigh resection specimen demonstrated a high-grade malignant osteoid-producing neoplasm, consistent with conventional osteosarcoma with both fibroblastic and osteoblastic features. H\&E stain, $\times 20$. $\mathbf{d}$ A biopsy of the colon at the hepatic flexure showed malignant cells within the lamina propria with similar morphology to the original specimen. H\&E stain, $\times 20$. There was no overlapping epithelial dysplasia or keratin expression within the cells, arguing against a new colorectal primary. Biopsy of an omental nodule showed similar histologic features. CT, computed tomography.

He was admitted to the hospital and a CT of the abdomen was obtained. It revealed peritoneal thickening, ascites, small bowel obstruction, omental stippling, hepatic lesions, and bilateral adrenal nodules (Fig. 2a, b). A biopsy of the colon at the hepatic flexure showed malignant cells within the lamina propria with similar morphology to the original osteosarcoma 
Table 1. Papers that met the inclusion criteria for reports of primary osteosarcoma of bone with metastases to the abdomen

\begin{tabular}{lcc}
\hline Number of papers $^{1}$ & \multicolumn{2}{c}{38} \\
\hline Year of publication & & $1963-2017$ \\
Total number of patients & $n=1$ & 40 \\
Patients per paper & $n=2$ & 36 \\
& 2 \\
\hline
\end{tabular}

${ }^{1}$ Does not include the current publication.

specimen. There was no overlying epithelial dysplasia or keratin expression within the cells, arguing against a new colorectal primary tumor. Biopsy of an omental nodule demonstrated similar histologic features, confirming metastatic osteosarcoma. Abdominal symptoms were addressed with colonic stenting and palliative paracentesis, but the patient declined precipitously and ultimately developed tachycardia, lactic acidosis, and leukocytosis, succumbing to sepsis 4 weeks after onset of abdominal pain, 28 months after initially presenting with thigh pain.

\section{Literature Review}

\section{Methods}

A literature review was performed to identify all papers reporting on patients with primary osteosarcoma of bone with documented metastasis to the abdomen. The PubMed database was queried for abdominal metastases under the "osteosarcoma" and "osteogenic sarcoma" medical subject heading, using the keywords "metastasis," "extra-pulmonary," "extra-skeletal," "gastrointestinal," "abdomen," "peritoneum," stomach," "duodenum," "liver," "pancreas," "jejunum," "ileum," "colon," "omentum," and "bowel." Papers were included if they (1) reported on human patients with primary osteosarcoma of bone with metastatic disease documented to the abdomen, (2) had complete, discernible data from initial presentation to advent of abdominal metastatic disease, and (3) were written in English. Papers with incomplete follow-up were included for assessment of presentations but excluded from the outcome/survival calculations. The exclusion criteria consisted of nonhuman subjects, patients with primary osteosarcoma of the abdomen or soft tissues, papers with incomplete data for presentation or follow-up; indiscernible data from patients with other cancers, and papers not written in English.

Two reviewers (R.S. and J.B.) read each paper for potential inclusion or exclusion. In cases of dispute, a tiebreaker (J.G.) determined the adequacy of the paper for the purposes of this review. The data from the included papers were collated on a spreadsheet, and descriptive statistics were then calculated for demographics, presentation, and outcomes.

\section{Results}

The PubMed search query returned a total of 118 papers that met consideration for review. After review, 38 papers met the inclusion criteria, reporting on a total of 40 patients (Table 1) [12-49]. Including the 2 patients from this series, 42 patients with primary osteosarcoma of the bone with subsequent abdominal metastases were available for review. 
Table 2. Demographics and outcomes of patients with primary osteosarcoma of bone with metastases to the abdomen, as reported in the medical literature and the current series

\begin{tabular}{|c|c|c|c|c|}
\hline & & $\begin{array}{l}\text { All } \\
\text { patients }\end{array}$ & $\begin{array}{l}\text { Patients with } \\
\text { metastatic disease } \\
\text { on diagnosis }\end{array}$ & $\begin{array}{l}\text { Patients without } \\
\text { metastatic disease } \\
\text { on diagnosis }\end{array}$ \\
\hline \multicolumn{2}{|l|}{ Number of patients } & 42 & 6 & 36 \\
\hline \multirow[t]{2}{*}{ Sex } & Male & 21 & 2 & 19 \\
\hline & Female & 21 & 4 & 17 \\
\hline \multirow[t]{2}{*}{ Age at diagnosis (years) } & Average & 22 & & \\
\hline & Range & $8-64$ & & \\
\hline \multirow[t]{7}{*}{ Site of primary disease } & Humerus & 2 & 0 & 2 \\
\hline & Pelvis & 1 & 0 & 1 \\
\hline & Proximal femur & 1 & 0 & 1 \\
\hline & Distal femur & 22 & 5 & 17 \\
\hline & Proximal tibia & 11 & 0 & 11 \\
\hline & Distal tibia & 0 & 0 & 0 \\
\hline & Other & 5 & 1 & 4 \\
\hline \multirow[t]{3}{*}{ Site of first documented metastasis ${ }^{1}$} & Lung & 35 & 5 & 30 \\
\hline & Bone & 0 & 0 & 0 \\
\hline & Peritoneum & 9 & 1 & 8 \\
\hline \multicolumn{2}{|l|}{$\begin{array}{l}\text { Number of patients with metastasis to } \\
\text { peritoneum only }\end{array}$} & 7 & 1 & 6 \\
\hline \multirow{2}{*}{$\begin{array}{l}\text { Time to first metastasis after initial } \\
\text { presentation (months) }\end{array}$} & Average & & NA & 29.7 \\
\hline & Range & & NA & 6-108 \\
\hline \multirow{2}{*}{$\begin{array}{l}\text { Time from initial diagnosis to abdominal } \\
\text { metastasis (months) }\end{array}$} & Average & 45.1 & 29.2 & 47.7 \\
\hline & Range & $0-132$ & $0-48$ & 14-132 \\
\hline \multirow{2}{*}{$\begin{array}{l}\text { Time from diagnosis of abdominal metastasis } \\
\text { to death (months) }{ }^{2}\end{array}$} & Average & 7.3 & 6.5 & 7.5 \\
\hline & Range & $1-42$ & 3-14 & $1-42$ \\
\hline \multicolumn{2}{|l|}{$\begin{array}{l}\text { Two-year survival after diagnosis of abdominal } \\
\text { metastasis }\end{array}$} & $27.2 \%$ & & \\
\hline \multicolumn{2}{|l|}{$\begin{array}{l}\text { Five-year survival after diagnosis of abdominal } \\
\text { metastasis }\end{array}$} & $10.9 \%$ & & \\
\hline \multicolumn{5}{|c|}{$\begin{array}{l}{ }^{1} \text { Numbers add up to } 44 \text { due to } 2 \text { patients having concurrent pulmonary and abdominal metastatic disease on follow-up. } \\
2 \text { Time from diagnosis of abdominal disease to death excludes papers that do not provide a time to death. Four papers had a } \\
\text { total of } 4 \text { patients who survived }>2 \text { years after abdominal metastasis (alive at } 24,31,32 \text {, and } 62 \text { months), but these reports did } \\
\text { not follow until time of death and are excluded from this assessment. However, all censured data are reflected in Kaplan-Meier } \\
\text { curve calculations and the } 2 \text { - and 5-year survival rates. }\end{array}$} \\
\hline
\end{tabular}

Descriptive statistics of the demographics, initial presentation and, outcomes of these 42 patients are presented in Table 2 .

Twenty-one males and 21 females are represented in this group, with a mean age of 22.1 years (Table 2). Twenty-nine patients were 21 years or younger at the time of diagnosis (69\%). The majority (78.5\%) had primary osteosarcoma about the knee, with $52.4 \%$ in the distal femur and $26.2 \%$ in the proximal tibia. One patient did not receive neoadjuvant chemotherapy while the rest did. Original local control was completed with amputation in 12 cases, wide resection limb salvage alone in 27 cases, and radiation combined with limb salvage 


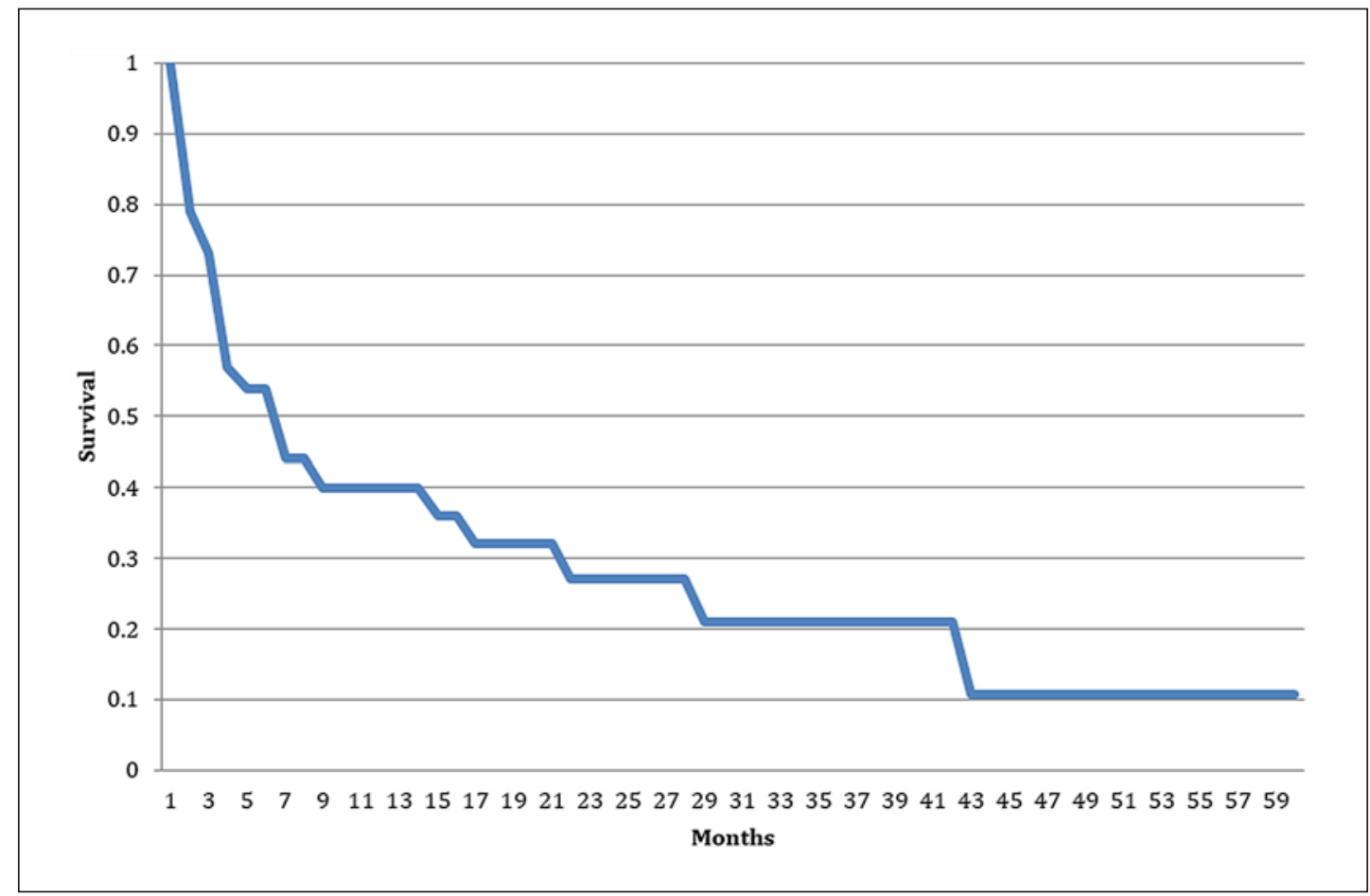

Fig. 3. Kaplan-Meier curve of survival after diagnosis of osteosarcoma metastatic to the abdomen, from the review of the literature and current cases.

surgery in 3 cases. When presenting with metastatic disease to the abdomen, 10 patients presented with intussusception (23.8\%).

Incomplete data for survival after diagnosis of metastatic osteosarcoma to the abdomen were noted in 10 subjects, while 8 papers did not comment on the survival of their patients at all. One patient remained alive beyond 5 years at the time of publication (62 months) [38], while 3 others were alive at their last follow-up beyond 2 years $(24,31$, and 32 months) [35, $39,44]$. Of the 24 patients with known time to death, 18 died of disease within 6 months of abdominal metastases (75\%), with 7 of those succumbing to disease within the month of onset of abdominal symptoms (29.2\%). A Kaplan-Meier survival curve was made with the available data, demonstrating a 5 -year survival of $10.9 \%$ after the diagnosis of metastatic osteosarcoma of the bone to the abdomen (Fig. 3).

\section{Discussion}

Primary osteosarcoma of bone is an aggressive malignancy with a metastatic pattern that favors the lungs primarily and the bones secondarily. Nonpulmonary, nonosseous metastases of osteosarcoma have been described in the literature, but the rare nature of this metastatic pattern has precluded the systematic study of these events. In our search of the literature, we found 38 case reports of osteosarcoma metastasis to the abdomen, of which 36 papers presented a single patient. Autopsy reports from early osteosarcoma research would, however, suggest that nonpulmonary, nonosseous metastasis of osteosarcoma is not as rare as the literature or clinical presentation may suggest [8-10]. In their report from 1975, Jeffree 
et al. [8] noted that the clinically evident incidence of extrapulmonary metastasis of osteosarcoma was $33 \%$ in their series, while the rate of extrapulmonary metastasis on autopsy rose, in that same group, to $83 \%$. While these percentages include osseous as well as nonosseous metastases, they do suggest a potential within the biology of osteosarcoma to spread outside of the lungs and bones. Indeed, the literature does not include a recent, large cohort of osteosarcoma patients in which the incidence of metastatic disease to nonpulmonary, nonosseous sites has been investigated.

The case reports and review of the literature described in this paper would suggest that the development of abdominal metastasis in osteosarcoma is a poor prognostic indicator, with very limited survivability beyond 2-3 years. Twenty-four of the 42 patients found in the literature had known time to death after diagnosis of abdominal metastases. Eighteen of these patients died within 6 months of the diagnosis, with 7 of those succumbing to disease within 1 month of abdominal symptom onset. Only 1 patient survived and was followed beyond 5 years after developing abdominal metastases, while 3 others were alive at last follow-up after 2 years (alive at 24, 31, and 32 months). Caution must be used however when interpreting these findings. There may be differences in the character of the disease when it presents as acutely symptomatic in the abdomen, as it did in our cases, and disease that may be found in the asymptomatic patient on a dedicated surveillance regimen.

Given the small numbers of patients noted in the literature and the poor prognosis of patients with metastatic osteosarcoma to the abdomen, the optimal timing and extent of sarcoma surveillance screening for nonpulmonary, nonosseous osteosarcoma metastasis is not known. Currently, the National Comprehensive Cancer Network recommends that the practitioner "consider PET-CT and/or bone scan" during restaging and posttreatment surveillance of osteosarcoma, which is in addition to imaging of the primary site and the lungs [11]. Due to our experience with 2 patients in 2 years presenting with osteosarcoma metastasizing to the abdomen, we suggest evaluating posttreatment osteosarcoma surveillance patients with an appropriate screening history and physical examination, and consideration of PET-CT, if warranted by that history or physical examination.

\section{Conclusion}

While the true incidence of nonpulmonary, nonosseous metastasis of osteosarcoma is not known, the scarcity of reports in the literature suggests that this is a rare event. As presented, abdominal metastasis of osteosarcoma is often a late manifestation and terminal prognostic indicator. Nonetheless, early detection and prompt intervention of this less common site of disease may improve patient care and palliative therapy.

\section{Acknowledgments}

We would like to acknowledge Mazdak A. Khalighi, MD for assistance with assessment and description of the pathology slides, and Sarah Shaw, BS for work on data collection of the case reports and early collation of data. Finally, we would like to acknowledge and thank the patients and their families, who graciously allowed us to present their cases so that the sarcoma community may better understand this devastating disease and improve our ability to care for patients afflicted with this malignancy.

\section{Karger's}




\section{Case Reports in Oncology}

\begin{tabular}{l|l}
\hline Case Rep Oncol 2021;14:647-658 \\
\hline DOI: 10.1159/000515195 & $\begin{array}{l}\text { @ 2021 The Author(s). Published by S. Karger AG, Basel } \\
\text { www.karger.com/cro }\end{array}$ \\
\hline
\end{tabular}

Serpico et al.: How Rare Is Osteosarcoma Metastasis to the Abdomen?

\section{Statement of Ethics}

Informed written consent was obtained from the patients or their guardians for the preparation and presentation of these case reports, including associated pathology and clinical imaging.

\section{Conflict of Interest Statement}

There were no professional nor financial conflicts of interest between any of the authors, patients, staff involved in the production of the manuscript, nor the medical care of the patients in this case report.

\section{Funding Sources}

This research did not receive any specific grant from funding agencies in the public, commercial, or not-for-profit sectors. No funding was provided in the development or completion of this work. None of the authors received payments or services, either directly or indirectly, from a third party in support of any aspect of this work. None of the authors has had any relationships, or has engaged in any other activities, that could be perceived to influence or have the potential to influence what is written in this work.

\section{Author Contributions}

R. Serpico was involved in the conceptualization, methodology, validation, data curation, and writing of this paper. J. Brown was involved in the methodology, validation, formal analysis, data curation, and writing of this paper. A. Blank, K. Jones, and R.L. Randall were involved in conceptualization, methodology, validation, and writing of this paper.J. Groundland was involved in the conceptualization, methodology, validation, data curation, and writing of this paper.

\section{References}

1 Mirabello L, Troisi RJ, Savage SA. Osteosarcoma incidence and survival rates from 1973 to 2004: data from the Surveillance, Epidemiology, and End Results Program. Cancer. 2009;115(7):1531-43.

2 Damron TA, Ward WG, Stewart A. Osteosarcoma, chondrosarcoma, and Ewing's sarcoma: National Cancer Data Base Report. Clin Orthop Relat Res. 2007;459:40-7.

3 Ottaviani G, Jaffe N. The epidemiology of osteosarcoma. Cancer Treat Res. 2009;152:3-13.

4 Jaffe N. The potential for an improved prognosis with chemotherapy in osteogenic sarcoma. Clin Orthop Relat Res. 1975;113:111-8.

5 Price CH, Zhuber K, Salzer-Kuntschik M, Salzer M, Willert HG, Immenkamp M, et al. Osteosarcoma in children. A study of 125 cases. J Bone Joint Surg Br. 1975;57(3):341-5.

6 Sinks LF, Mindell ER. Chemotherapy of osteosarcoma. Clin Orthop Relat Res. 1975;111:101-4.

7 Smeland S, Bielack SS, Whelan J, Bernstein M, Hogendoorn P, Krailo MD, et al. Survival and prognosis with osteosarcoma: outcomes in more than 2000 patients in the EURAMOS-1 (European and American Osteosarcoma Study) cohort. Eur J Cancer. 2019;109:36-50.

8 Jeffree GM, Price CH, Sissons HA. The metastatic patterns of osteosarcoma. Br J Cancer. 1975;32(1):87-107.

9 Bacci G, Avella M, Picci P, Briccoli A, Dallari D, Campanacci M. Metastatic patterns in osteosarcoma. Tumori. 1988;74(4):421-7.

10 Uribe-Botero G, Russell WO, Sutow WW, Martin RG. Primary osteosarcoma of bone. Clinicopathologic investigation of 243 cases, with necropsy studies in 54. Am J Clin Pathol. 1977;67(5):427-35. 
11 National Comprehensive Cancer Network . NCCN Clinical Practice Guidelines in Oncology. Bone Cancer. 2017; 2(2017):1-88.

12 Aarvold A, Bann S, Giblin V, Wotherspoon A, Mudan SS. Osteosarcoma metastasising to the duodenum and pancreas. J Bone Joint Surg Br. 2007;89(4):542-4.

13 Abbo O, Pinnagoda K, Micol LA, Beck-Popovic M, Joseph JM. Osteosarcoma metastasis causing ileo-ileal intussusception. World J Surg Oncol. 2013;11(1):188.

14 Avcu S, Akdeniz H, Arslan H, Toprak N, Unal O. A case of primary vertebral osteosarcoma metastasizing to pancreas. JOP. 2009;10(4):438-40.

15 Badiu DC. A rare cause of bowel obstruction: peritoneal metastases in osteosarcoma at the tibia in a young female patient with brain metastasis. Case Report. Chirurgia (Bucur). 2016;111(3):274-8.

16 Chan HH, Chan JK, Ng WM, Shek TW, Chan FL. Lace-like enhancement pattern of osteosarcoma of rib and liver metastasis in CT scans. Australas Radiol. 2001;45(3):305-8.

17 Chandramohan K, Somanathan T, Kusumakumary P, Balagopal PG, Pandey M. Metastatic osteosarcoma causing intussusception. J Pediatr Surg. 2003;38(10):E1-3.

18 Costa A, Fustaino L, Mosca F. Metastatic osteosarcoma involving the colon and ileum. Gastrointest Endosc. 2001;54(1):75.

19 Costa CM, de Camargo B, Bagietto R, Alcantra PS, Chojniak R, Sredni ST. Abdominal recurrence of osteogenic sarcoma: a case report. J Pediatr Hematol Oncol. 1998;20(3):271-3.

20 El Ajmi M, Ksantini R, Chebbi F, Makni A, Rebai W, Daghfous A, et al. Abdominal metastasis of a parosteal osteosarcoma of the femur: an unusual cause of large-bowel obstruction. Acta Chir Belg. 2009;109(5):633-4.

21 Ganguli SN, Hamilton P, Hanna S, Morava-Protzner I. Small bowel intussusception secondary to osteogenic sarcoma metastasis: case report. Can Assoc Radiol J. 1999;50(3):170-2.

22 Glass RJ, Eftekhari F, Kleinerman ES, Jaffe N, Nachman J. Osteosarcoma metastatic to the pancreas in young patients. Clin Radiol. 1996;51(4):293-4.

23 Goldberg SL, Fink V, Goldsmith B. Metastatic osteogenic sarcoma of the ileum. Intussusception and intestinal obstruction. Arch Surg. 1963;86:233-4.

24 Goyal S, Julka PK. Recurrent osteosarcoma with calcified liver metastases: uncommon development of a common disease. J Cancer Res Ther. 2017;13(1):139-41.

25 Hirota T, Konno K, Fujimoto T, Ohta H, Kato S, Hara K. Unusual late extrapulmonary metastasis in osteosarcoma. Pediatr Hematol Oncol. 1999;16(6):545-9.

26 Horiuchi A, Watanabe Y, Yoshida M, Yamamoto Y, Kawachi K. Metastatic osteosarcoma in the jejunum with intussusception: report of a case. Surg Today. 2007;37(5):440-2.

27 Horiuchi K, Susa M, Mukai M, Nishimoto K, Suzuki Y, Nakayama R, et al. Osteosarcoma with metastasis to the stomach. J Orthop Sci. 2010;15(2):265-8.

28 Hung GY, Chiou T, Hsieh YL, Yang MH, Chen WY. Intestinal metastasis causing intussusception in a patient treated for osteosarcoma with history of multiple metastases: a case report. Jpn J Clin Oncol. 2001;31(4): $165-7$.

29 Jin P, Wang W, Su H, Sheng JQ. Osteosarcoma metastasizing to pancreas confirmed by endoscopic ultrasoundguided fine-needle aspiration. Endoscopy. 2014;46(Suppl 1 UCTN):E109-10.

30 Karacalioglu O, Ilgan S, Kuzhan O, Emer O, Ozguven M. Disseminated metastatic disease of osteosarcoma of the femur in the abdomen: unusual metastatic pattern on Tc-99m MDP bone scan. Ann Nucl Med. 2006;20(6): 437-40.

31 Khan AS, Crowe DR, Trevino JM, Eloubeidi MA. Multiple metastases to the pancreas from primary maxillary osteosarcoma: diagnosis with EUS-guided FNA. Gastrointest Endosc. 2011;73(6):1320-2.

32 Kubo T, Furuta T, Johan MP, Yoshizuka M, Ochi M, Adachi N. Long-term survival after sporadic and delayed metastases of conventional osteosarcoma: a case report. Medicine (Baltimore). 2017;96(18):e6824.

33 Lasithiotakis K, Petrakis I, Georgiadis G, Paraskakis S, Chalkiadakis G, Chrysos E. Pancreatic resection for metastasis to the pancreas from colon and lung cancer, and osteosarcoma. JOP. 2010;11(6):593-6.

34 Lin JT, Yen CC, Wang WS, Chiou TJ, Liu JH, Wu HT, et al. Case report: Unusual peritoneal spreading by metastatic osteosarcoma of the tibia. Br J Radiol. 2003;76(905):337-8.

35 Moses J, Gibson N, Plesec T, Plautz G, Kay M, Soldes O. Metastatic osteosarcoma to the stomach and ascending colon in a pediatric patient causing gastrointestinal hemorrhage. J Pediatr Surg. 2013;48(4):e1-3.

36 Mozes M, Mozes G, Greiff M, Sacks M. Metastatic osteogenic sarcoma of small intestine with intussusception. Isr J Med Sci. 1988;24(8):426-8.

37 Onoro G. Unusual sites of extrapulmonary metastases of osteosarcoma after several lines of treatment. Pediatr Hematol Oncol 2011;28(7):604-8.

38 Overberg-Schmidt US, Baumgarten E, Bassir C, Becker M, Unger M, Henze G. The stomach and pulmonary interlobular space as unusual sites of osteosarcoma. Pediatr Hematol Oncol. 1999;16(1):61-6.

39 Panizo-Santos A, Sola I, Lozano M, de Alava E, Pardo J. Metastatic osteosarcoma presenting as a small-bowel polyp. A case report and review of the literature. Arch Pathol Lab Med. 2000;124(11):1682-4.

40 Pirayesh E, Rakhshan A, Amoui M, Rakhsha A, Poor AS, Assadi M. Metastasis of femoral osteosarcoma to the abdominal wall detected on 99m Tc-MDP skeletal scintigraphy. Ann Nucl Med. 2013;27(5):478-80.

41 Rejin K, Aykan OA, Omer G, Ensar Y, Bilge B, Inci A, et al. Intra-abdominal metastasis in osteosarcoma: survey and literature review. Pediatr Hematol Oncol. 2011;28(7):609-15. 
42 Strauss SJ, McTiernan A, Whelan JS. Late relapse of osteosarcoma: implications for follow-up and screening. Pediatr Blood Cancer. 2004;43(6):692-7.

43 Strong VE, Shalkow J, Antonescu CR, Meyers P, La Quaglia MP. Osteosarcoma with delayed metastasis to the stomach. J Pediatr Surg. 2007;42(4):737-9.

44 Takaue Y, Slopis JM, Anzai T, Robertson R, Jaffe N. Successful treatment of pulmonary and abdominal metastatic osteosarcoma. Med Pediatr Oncol. 1985;13(3):126-8.

45 Webster VJ, Arons I. Intussusception secondary to osteogenic sarcoma metastasis. Br J Clin Pract. 1987;41(2): 628-9.

46 Westra A, Schrijvers D, Somville J, Van Schil P, Hubens G, Van Oosterom A. Late peritoneal metastasis in a patient with osteosarcoma. Ann Oncol. 1998;9(8):907-11.

47 Wootton-Gorges SL, Stein-Wexler R, West DC. Metastatic osteosarcoma to the small bowel with resultant intussusception: a case report and review of the literature. Pediatr Radiol. 2003;33(12):890-2.

48 Yeh SN, Lu MY. Peritoneal metastasis in osteosarcoma: report of one case. Acta Paediatr Taiwan. 2005;46(4): 230-4.

49 Chan RS, Kumar G, Vijayananthan AA. Rare occurrence of bilateral breast and peritoneal metastases from osteogenic sarcoma. Singapore Med J. 2013;54(3):e68-71. 